\title{
The Empirical Study on Operating Efficiency of Agricultural Cooperatives in Langao
}

\author{
Xingang Wang ${ }^{1}$, Lu Sun ${ }^{2} \&$ Yanxin Zhang ${ }^{2}$ \\ ${ }^{1}$ Zhejiang Wanli University, China \\ ${ }^{2}$ Harbin University of Commerce, Harbin 150028, China \\ Correspondence: Xingang Wang, Zhejiang Wanli University, Ningbo, China
}

Received: May 20, 2012 Accepted: July 26, $2012 \quad$ Published: September 1, 2012

doi:10.5539/ijbm.v7n17p60 URL: http://dx.doi.org/10.5539/ijbm.v7n17p60

\begin{abstract}
The purpose of this paper is to investigate the operating efficiency of agricultural cooperatives in Langao which is remote city in North East of China. Based on the Farrell's concept of efficiency, this paper selected inputs and output factors for agricultural cooperatives by using fuzzy Delphi method (FDM), there are four input factors among them, namely the number of employment, assets, operating expenses and management costs, but there are two output factors, namely the number of members and operating income.

Furthermore, this paper used data envelopment analysis to establish efficiency boundary function and obtained the operating efficiency of agricultural cooperatives. In terms of all of the agricultural cooperatives, there are total 14 agricultural cooperatives in the $104 \mathrm{DMU}$, and their values of operating efficiency are both one. In addition, business entities and models of various types of agricultural cooperatives are not the same, so this study fit vegetables and fruit and livestock farming cooperatives, which was proposed by Golany and Roll in 1989. In the terms of efficiency of vegetables and fruits of agricultural cooperatives, the operating efficiency values of ten ones are one, however, the livestock operators with the operating efficiency who have twelve.

Finally, the use of AHP further distinguished the efficient operation of agricultural cooperatives in order to select the best business model. On all of the agricultural cooperatives, Lin-Xiang pig production cooperatives in Langao area were the best operating efficiency. Solely in terms of vegetables and fruit agricultural cooperatives, Crane Luyuan cooperatives were the highest efficient. In terms of livestock farming cooperatives, the pig production cooperatives in Lin township had the best operational efficiency and could be a model.
\end{abstract}

Keywords: agricultural cooperatives, data envelopment analysis, fuzzy Delphi method, AHP

\section{Introduction}

Agricultural cooperatives mainly considered common needs and cooperative willingness and obeyed the principle of equality on the basis of self-help groups for farmers through co-operation in order to overcome the difficulties encountered by agricultural operations, reduce production costs, improve operational efficiency and increase the competitiveness. Its target of organization operations is to achieve economic, educational, social, political and many other features, which the individual business can not get. Agricultural cooperatives hope that through mutual cooperation among members resources can be used to create competitive advantage and to achieve common goal. Therefore, the level of operational efficiency will directly affect the efficiency of agricultural production and distribution, furthermore, and farmers' incomes. Thus how to improve and strengthen the operating efficiency of agricultural cooperatives to enhance their competitiveness will be an important topic of the agricultural cooperative organizations.

In general, inputs and outputs of profit organization are easy to confirm and quantify, there often exists a function between inputs and outputs. However, for non-profit organization, its most of assessment criteria is multiple and difficult to quantify, in fact, the function relation between inputs and outputs is not significant. As non-profit organization, function relation of the agricultural cooperatives is not significant and lack relevant research. It is more accurate to measure the operating efficiency, the selection of input and output factors should be deep studied. At present, there are 200 Agricultural cooperatives in Langao area. Which agricultural cooperatives is the best efficient and as the business model of inefficient operation, is also worthy of discussion. 
Therefore, the purpose of this study can be listed as follows:

- First, understand the operating status of agricultural cooperatives in Langao.

- Second, talk about input and output factors of the operating efficiency as the basis of measurement of its operating efficiency.

- Third, assess the operating efficiency of agricultural cooperatives.

- Fourth, analyze the business model of agricultural cooperatives to provide references for various types of agricultural cooperatives.

\section{Literature Review: Related to Agricultural Cooperatives}

Agricultural cooperatives is one of the most important groups of farmers in Langao, whose main function is to seek the greatest economic benefit for members in the process of agricultural production and sales, so as to promote agricultural development, rural prosperity and the improvement of lives of farmers. However, currently agricultural cooperatives exist widespread problems such as the lack of funds and management talent, various organizational scales, the lack of cooperative awareness and inadequate regulations. So its function can not be completely realized. Thus, scholars have proposed some relevant research on the operating efficiency of agricultural cooperatives and hoped to improve the management system of agricultural cooperatives and perform their functions.

$\mathrm{Li}$ (2010) et al pointed out the operation mode of single agricultural cooperatives and the distribution below the economies of scale led to competitive advantage of cooperatives to continue to fall down, because of joining WTO, agricultural cooperatives should integrate all agricultural resources and unit all farmers' organizations by the way of social cooperation and strategic alliances to create a win-win situation. Cai(2011) and Zhang(2010) also discussed that the integration of agricultural cooperatives should be accelerated in order to expand its scale of operation, and then increase the interests of farmers and maintain output of agricultural sector.

In addition, Zhang(2011, Zhang(2010)and Zeng (2011) referred to that the appropriate personnel management system, the establishment of corporate image and the use of strategic information systems will make agricultural cooperatives more efficient and competitive to get the best return on investment.

Agricultural cooperatives are the most direct and effective organizations, which can enhance agricultural competitiveness and increase farmers' income. So the level of its operational efficiency will have impact on agricultural sector. Then scholars put forward variety of perspectives to measure the operating efficiency of agricultural cooperatives. $\mathrm{Xu}(2010)$ believed that the dual nature of organization and social unit made agricultural cooperatives have economic value and ethical value, the economic value comes from the production or sale of goods and services of the fiscal exchange value, but ethical value is indicated by the principle of agricultural cooperatives. Therefore, the operating efficiency is assessed by the economic value, the ethical value of agricultural cooperatives should be also considered. Xu (2011) pointed out that the measure of operating efficiency of agricultural cooperatives should be given comprehensive assessment, which mainly includes service, integrity and development, its indicators of evaluation should be built by ratio analysis method. Dong(2010) attempted to explore the operating efficiency of agricultural cooperatives on the basis of four aspects, namely personnel expenses, the amount of investment fund, the community chest and provident fund, and to analyze their factors.

However, the above studies only talked about the assessment indicators of operating efficiency of agricultural cooperatives and did not analysis the measure of operating efficiency. In this paper, the operating efficiency was calculated by DEA, this value was relative concept, so it can not only timely provide the relative data among agricultural cooperatives, but also the references of improving the efficiency on management.

\section{Status of the Operation of Agricultural Cooperatives}

Farmers engaged in farming, forestry, fisheries and livestock as a career and operated the cause of production by the pattern of cooperation, all of them are belong to parts of agricultural cooperation. According to Agricultural Cooperation Annual Reports in Langao, there were 200 agricultural cooperatives and 178,064 members in Langao by the end of 2010. Compared to agricultural cooperatives in 1997, the number of the establishment grew 2.21 times and the number of members is reduced by $10 \%$. In terms of types of agricultural cooperatives, livestock agricultural cooperatives grew 10.33 times on the number of establishment, which was followed by fruit and flower agricultural cooperatives, respectively increased 7.6 and 5 times, while forestry cooperatives showed negative growth.

In terms of the number of members, members of flower agricultural cooperatives grew 8.6 times, which followed 
by livestock agricultural cooperatives, their members grew 5.9 times compared to 1977 .

In terms of balance of payments, the total income includes operating income and out of operating income. Among them, the operating income mainly contains production income, distribution income, sales income, the supply of business income, the use of business income, consumption income, utility operating income, labor income, insurance income and other revenue. Total expenditure includes operating expenses, management fees and out of business of expenses. However, total revenue and expenses were 1,016,708 million and 1,06,748 million as shown in table1.

Table 1. The revenue of summary of agricultural cooperatives in Langao unit: million, $\%$

\begin{tabular}{llllll}
\hline & 1996 & 1997 & 1998 & 1999 & 2000 \\
\hline Operating income & 890,590 & 550,322 & 212,101 & 745,115 & 975,9155 \\
& $(95.18)$ & $(97.71)$ & $(95.41)$ & $(94.74)$ & $(95.91)$ \\
The income out of business & 45,061 & 12,857 & 10,196 & 41,404 & 41,601 \\
& $(4.82)$ & $(3.48)$ & $(5.53)$ & $(5.26)$ & $(4.09)$ \\
Total income & 935,651 & 563,179 & 222,297 & 786,519 & $1,016,708$ \\
& $(100.00)$ & $(100.00)$ & $(100.00)$ & $(100.00)$ & $(100.00)$ \\
Operating expense & 785,743 & 492,516 & 158,826 & 946,606 & 858,581 \\
& $(83.00)$ & $(85.20)$ & $(71.08)$ & $(81.09)$ & $(82.81)$ \\
Management fees & 122,573 & 70,478 & 53,950 & 171,481 & 13,2265 \\
& $(13.00)$ & $(12.19)$ & $(24.14)$ & $(14.69)$ & $(12.76)$ \\
The expense of out of business & 34,450 & 15,096 & 10,669 & 49,317 & 46,275 \\
& $(4.00)$ & $(2.61)$ & $(4.78)$ & $(4.22)$ & $(4.46)$ \\
Total expenditure & 942,766 & 578,536 & 223,445 & $1,167,404$ & $1,036,748$ \\
Balance of payments & $(100.00)$ & $(100.00)$ & $(100.00)$ & $(100.00)$ & $(100.00)$ \\
\hline
\end{tabular}

Data source: the Statistical Yearbook of Agriculture and Rural Statistical Yearbook

Note: bracket refers to the percentage of factors

In recent years, the income of agricultural cooperatives showed a decreasing trend, but has gradually recovered. In terms of expenditure, the proportion of operating expenses was the highest and more than $80 \%$, which followed by management expenses. From the data of table1, agricultural cooperatives were at a loss in Langao county, so how to effectively make use of resources, to get the maximum of output, to turnaround operation from loss to profit and to improve efficiency and competitiveness will be a subject worthy of attention.

\section{Theoretical Model}

\subsection{Data Envelopment Analysis}

DEA was first proposed by Charnes, Cooper and Rhodes in 1978, this suggestion was from non-parametric measurement of Farrell, which aimed at non-profit organization and industries with a wide range of products and measured the relative efficiency value of multiple input and output. The efficient frontier was established by the most efficient DMU and compared to its actual efficiency in order to the relative efficiency of DUM. If the efficiency is on the frontier, it is relative efficient, if not, the efficiency is relatively inefficient.

\subsection{Fuzzy Delphi Method}

Delphi Method is experts forecast method and also a kind of group decision-making method. This method was proposed by Olaf Helmer in RAND Corporation, the views of experts were through structured communication program to obtain the prediction method of consistent results. However, the process of implementation of Delphi Method is rather complicated and time-consuming, whose input costs is very high and recovery rate is low, and easy to produce fuzzy and distorted views of experts and other shortcomings, so this study still adopt fuzzy Delphi method as input and output factors of agricultural cooperatives. The establishment of fuzzy Delphi 
method first need construct triangular fuzzy number by using the generalized model of average, then need to filter input and output factors of agricultural cooperatives through the configuration of the threshold value(S).

\subsubsection{The Establishment of Triangular Fuzzy Numbers}

In this study, the maximum and minimum of the average function was the two end points of triangular fuzzy numbers of expert consensus. Because Satty believed the geometric average expressed expert consensus in 1980, the effect is best, and in practical applications, the geometric average is widespread used and its value only can meet the definition of fuzzy inverted value matrix.

\subsubsection{The Selection of Input and Output Factors}

After the above steps, we obtained triangular fuzzy function and used it to select input and output factors. Because the maximum and minimum were more extreme in this function, the geometric average can represent the majority of expert advice in the decision-making group. Therefore, the geometric mean of the triangular fuzzy function is used membership function to represent the evaluation of input and output factors of expert consensus. Finally, according to the threshold value, select representative and appropriate input and output factors, namely, $\delta_{i j} \geq S$ those factors is assessment of factors, if $\delta_{j i}<S$ the factors should be removed, we set up the threshold value on the basis of the median of assessment scores for screening criteria, so the appropriate input and output factors will be selected by experts, those factors may measure the operating efficiency of agricultural cooperatives.

\subsection{The Analysis of AHP}

AHP was proposed by the United States Commissioner called Thomas L.Saaty. It was a systematic decision-making model and mainly used in uncertain circumstances and the decision with the majority of assessment criteria. AHP decomposed complex issues from high level to low level by using hierarchical structure, the system contained sub-system in order to illustrate a structural system, and make it a limited combination of multi-level relationship. Its purpose is to systematize the complex problem, different levels are given the level of decomposition, and find a comprehensive assessment of context by quantifying the judge, AHP will provide adequate information for decision-makers to select appropriate program and reduce the risk of making errors.

\section{Empirical Analysis of Operating Efficiency of Agricultural Cooperatives}

\subsection{Selection of Input and Output Factors}

When the use of DEA measured the operating efficiency of agricultural cooperatives, the appropriate input and output factors should be selected to efficiently assess the operational efficiency of the DMU. In order to select input and output factors combined with expert opinions and to avoid ambiguity in the process of visits, the input and output factors of agricultural cooperatives were filtered by fuzzy Delphi method this paper sent 13 questionnaires and the 11 valid questionnaires were returned and the response rate was about $85 \%$. Fremont pointed out that more than five participants generated public opinion can be used as a basis for analysis, and the expert interviewed covered industry, government and science, which are related to agricultural cooperatives, should be a fairly representative.

This paper selected seven input factors and three output factors of agricultural cooperatives, through the operation of the fuzzy Delphi method, the geometric mean was used as the consensus of expert evaluation, and the median of assessment score of input and output factors was used as the screening criteria, namely the threshold value was set to seven to select input and output factors, which can be enough to measure the operating efficiency of agricultural cooperatives. From table2 and table3, we can find some results as follows: when the value of geometric mean is greater than the one of threshold, there are total four input factors, namely the number of employees, assets, operating expenses and management fees. However, there are two output factors, namely the number of members and revenue.

Due to the assessment of DEA model, its input and output factors must comply with the assumption of isotonicity, in other words, any increase in investment should be followed by output. Therefore, according to input and output factors, those factors were selected by experts, to understand the degree of correlation by correlation analysis and finally confirm input and output factors. From the table 4, we can find the correlation coefficient between input factors and output factors, which shows those two kinds of factors are highly correlated, the information is in line with the requirements of DEA. 
Table 2. The triangular fuzzy of input factors of agricultural cooperatives

\begin{tabular}{lccc}
\hline Input factors & \multicolumn{3}{c}{ The scores of assessment } \\
\cline { 2 - 4 } & minimum & Geometric mean & maximum \\
\hline The number of employees & 5 & 7.9279 & 10 \\
assets & 7 & 8.1918 & 10 \\
Business expense & 6 & 8.1081 & 10 \\
Management fees & 5 & 7.1931 & 10 \\
The expense out of business & 1 & 3.7978 & 8 \\
Co-education expenses & 4 & 6.7811 & 9 \\
Welfare of members & 2 & 4.5411 & 8 \\
\hline
\end{tabular}

Table 3. The Triangular fuzzy of output factors of agricultural cooperatives

\begin{tabular}{lccc}
\hline Input factors & \multicolumn{3}{c}{ The scores of assessment } \\
\cline { 2 - 4 } & minimum & Geometric mean & maximum \\
\hline The number of members & 4 & 7.3804 & 10 \\
Operating income & 8 & 9.3199 & 10 \\
Income out of business & 1 & 4.5730 & 8 \\
\hline
\end{tabular}

Table 4. The correlation coefficient of input and output factors of agricultural cooperatives

\begin{tabular}{lllll}
\hline \multicolumn{1}{c}{ number of employees } & assets & Operating expenses & Management fees \\
\hline $\begin{array}{l}\text { The number of } \\
\text { members }\end{array}$ & 0.1831 & 0.5362 & 0.0165 & 0.2967 \\
\begin{tabular}{l} 
Operating income \\
\hline
\end{tabular} & 0.7820 & 0.6645 & 0.9818 & 0.4689 \\
\hline
\end{tabular}

\subsection{Analysis of Operating Efficiency of Agricultural Cooperatives}

According to the purpose of research and analysis, combined CCR and BCC, the input-oriented model was applied to the empirical analysis on operating efficiency measurement of agricultural cooperatives. The efficiency value of DEA was calculated by IDEAS software, the results of analysis were described as follows:

\subsubsection{Analysis of Operating Efficiency of Agricultural Cooperatives}

Rule of thumb proposed by Golany and Roll in 1989 means that the number of DMU must be at least twice the sum of input and output factors in the use of DEA analysis model. Because of Agricultural Cooperation Annual Report in Langao, part of information of agricultural cooperatives is not recorded in detail, incomplete data are deleted, 104 agricultural cooperatives of data integrity are selected to be as empirical study, which complies with the limitation of the rule of thumb. In addition, to take the measure of DMU efficiency value into account, the inputs of agricultural cooperatives are easy to control, so the input-oriented combined CCR and BCC evaluated the operating efficiency of agricultural cooperatives.

The results of DEA efficiency assessment are very helpful to understand the relative operating efficiency among agricultural cooperatives. If the value of efficiency is one, DMU will be relatively effective. If not, DMU will be relatively ineffective. There are total 14 agricultural cooperatives with relatively efficient operating, respectively Dongfeng vegetables farmer cooperatives in Langao, Four ping vegetable farmer cooperatives in Langao, Four Seasons Yang fruit and vegetable production cooperatives, Zhongwu cooperatives, Junior Longzhen Fulcom fruits and vegetables farmer cooperatives, Nantou flower production cooperative, Hancock marketing professional cooperatives, Northern Taiwan broiler marketing cooperatives, Linhe pig production cooperatives, Qinba chicken farmer cooperatives, Progress livestock farmer cooperatives, Pear village cooperatives, Langao 
Overflow River fisheries insurance cooperatives and so on. All of their value is one, namely, those the operating efficiency of fourteen agricultural cooperatives achieved the desired state, while the remaining ninety agricultural cooperatives are belong to the relatively poor operating efficiency.

$\mathrm{Li}(2011)$ and Lou(2010) based on the efficiency value of the assessment, further divided DUM into strong efficiency, the efficiency of the edge, inefficiency of the edge and obvious inefficiency. Among them, strong efficiency means the efficiency value is one, the difference between the variables is zero, the strength hidden inefficient DMU is great, unless its input and output factors have significant change, or it should be able to maintain its efficiency value. The efficiency of the edge means that the efficiency value is one, the difference between the variable is not at least zero, such units as long as the input and output factors are increased or reduced, its efficiency value will be below one. Inefficiency of the edge refers to that the efficiency value is less than one but greater than 0.9 , its efficiency value is easy to enhance one, if the efficiency value is less than 0.9 , this unit is obviously inefficient, those units become efficient ones in the term will be more difficult. If the efficiency value of unit is less than 0.75 , unless input and output factors have major change, or they will continue to maintain inefficiencies. DEA efficiency value and the variable message are shown in the table 5 . There are fourteen DUM, whose operating efficiency is strong and the efficiency value is one and accounting for $13 \%$ of all the DMU, which are more concentrated in vegetables and fruit and livestock agricultural cooperatives, respectively five vegetables and fruit agricultural cooperatives and four livestock agricultural cooperatives, all of them have better operating efficiency. The operating efficiency of two DMU is between 0.9 and 1, which are obvious inefficiency and accounting for $2 \%$ of all the DMU, those are belong to livestock agricultural cooperatives and their relative operating efficiency is easy to raise. The operating efficiency vale of eighty-eight DMU is less than 0.9 and obvious inefficient, which are mainly concentrated in vegetable and fruit, tea, flower, fishery, livestock and other types of agricultural cooperatives, the operating efficiency value of tea agricultural cooperatives is the lowest with the average of 0.4231 , so the relative operating efficiency of tea agricultural cooperatives is rather poor as shown in the table 6.

Table 5. The classification of operating efficiency of agricultural cooperatives

\begin{tabular}{lcc}
\hline classification & DMU & Percent \\
\hline Strong efficiency & 14 & $13 \%$ \\
Edge of the inefficiency & 2 & $2 \%$ \\
Obviously inefficient & 88 & $85 \%$ \\
\hline
\end{tabular}

Table 6 . The average of operating efficiency of types of agricultural cooperatives

\begin{tabular}{c|ccccc} 
Efficiency value & $\begin{array}{c}\text { Operating } \\
\text { efficiency }\end{array}$ & $\begin{array}{c}\text { Technical } \\
\text { efficiency }\end{array}$ & $\begin{array}{c}\text { Allocative } \\
\text { efficiency }\end{array}$ & $\begin{array}{c}\text { Pure } \\
\text { technical } \\
\text { efficiency }\end{array}$ & $\begin{array}{c}\text { Scale } \\
\text { efficiency }\end{array}$ \\
\hline $\begin{array}{c}\text { Fruit and vegetable } \\
\text { tea }\end{array}$ & 0.4994 & 0.5101 & 0.9735 & 0.7354 & 0.6799 \\
flower & 0.4231 & 0.4250 & 0.9877 & 0.9750 & 0.6196 \\
fishery & 0.5360 & 0.5360 & 0.9997 & 0.7831 & 0.6797 \\
livestock & 0.4763 & 0.5012 & 0.9465 & 0.7017 & 0.7107 \\
forestry & 0.5178 & 0.5272 & 0.9732 & 0.7854 & 0.6588 \\
other & 1.0000 & 1.0000 & 1.0000 & 1.0000 & 1.0000 \\
average & 0.5295 & 0.4939 & 0.9952 & 0.8531 & 0.6081 \\
\hline
\end{tabular}

To sum up, the operating efficiency value of the majority of agricultural cooperatives are relatively obvious inefficiency. Because of the composition of technical and allocative efficiency, the average of allocative efficiency reached 0.9745 and was more than its technical efficiency, which indicates that the use of resources of agricultural cooperatives exist excessive waste, thus it should invest its resources for optimum use to enhance technology efficiency, further to improve its operating efficiency. In addition, technical efficiency is composed of technical efficiency and scale, and their average value is 0.7622 and 0.6722 , because pure technical efficiency is higher than the efficiency of scale, the main cause of inefficiency can be attributed to engage in the production at inappropriate scale. 
As Pengfang vegetables agricultural cooperatives a example, its operating efficiency value is 0.0212 and the lowest in all the agricultural cooperatives. Because operating expenses is too much, and with its growth the income can not increase, it's the value of technical efficiency is 0.0214 and less than allocative efficiency, the value of allocative efficiency is 0.9911 . Therefore, the main reason for operating inefficiency is technical inefficiency and not allocative inefficiency. Furthermore, the value of pure technical efficiency is 0.6364 and more than efficiency of scale with the value of 0.0336 , so we can see the reasons for technical inefficiency, the agricultural cooperatives engaged in production at inappropriate scale.

In addition, fruits and vegetables, tea, flowers, forestry, fisheries, livestock and other agricultural cooperatives have different business entities and model, so this study further meet the rule of thumb proposed by Golany and Roll in 1989, then the use of DEA analyze the operating efficiency of vegetables and fruit agricultural cooperatives.

\subsubsection{Analysis of the Efficiency of Vegetable Agricultural Cooperatives}

In terms of vegetables and fruit agricultural cooperatives, after the empirical analysis of DEA, ten vegetables and fruit agricultural cooperatives of all the DMU have efficient operating, which is Dongfeng vegetables cooperatives, Crane Luyuan Zhang River cooperatives, Gaoqiao vegetables and fruit cooperatives, Four ping vegetable farmer cooperatives, Four Seasons Yang fruit and vegetable production cooperatives, Zhongwu cooperatives, Xingmin vegetables cooperatives, Lixin vegetables and fruit cooperatives, Fuhong vegetables and fruit cooperatives and Yan door vegetables marketing, all of their efficiency value is one, while the operating efficiency of the remaining 32 agricultural cooperatives is rather poor.

The contents of table7 is the classification of operating efficiency of vegetables and fruit agricultural cooperatives, the operating efficiency of ten DMU is strong and its value is one, which indicating relative operating efficiency is better and accounting for $24 \%$ of DMU. There is a DMU with the value of operating efficiency between 0.9 and 1 , it is the edge of the inefficiency and accounting for $2 \%$ of all the DMU. The 31 DMU, their value of operating efficiency is less than 0.9 , is belong to obvious inefficiency and accounting for $74 \%$ of all the DMU.

Table 7. The classification of operating efficiency of vegetable and fruit agricultural cooperatives

\begin{tabular}{lcc}
\hline classification & DMU & percentage \\
\hline Strong efficiency & 10 & $24 \%$ \\
Edge of the inefficiency & 1 & $2 \%$ \\
Obviously inefficient & 1 & $74 \%$ \\
\hline
\end{tabular}

From the results of DEA efficiency analysis, we can know that operating efficiency value of majority of vegetables and fruit agricultural cooperatives are obvious inefficiency, because of the composition of technical and allocative efficiency, the value of allocative efficiency of vegetables and fruit agricultural cooperatives reached 0.8486 and higher than technical efficiency with the average value of 0.6729 , which indicates vegetables and fruit agricultural cooperatives exist the excessive waste of resources, therefore, the resources should be put into best use in order to improve technical efficiency and the operating efficiency. In addition, technical efficiency includes pure technical efficiency and scale efficiency, the average value of pure technical efficiency is 0.8660 and higher than scale efficiency with the average value of 0.7739 , which shows that vegetables and fruit agricultural cooperatives exist cases of inefficiencies due to the inappropriate scale of production.

As Pengfang vegetables cooperatives in Langao a example, the operating efficiency of cooperatives is lowest and its value is 0.1081 . its value of technical efficiency is 0.2338 and lower than allocative efficiency with the value of 0.4624 , so the main reason for the inefficient operating of vegetables agricultural cooperatives is technical inefficiency. Further study found that its value of pure technical efficiency is 0.8986 and higher than scale efficiency with the value of 0.2602 , the reason for technical inefficiency is that the vegetables agricultural cooperatives engaged in production at inappropriate scale.

\subsection{Reference Collection and Variable Analysis of Agricultural Cooperatives}

By the process of linear program of DEA, each DMU will be obtained a group of efficient reference point, namely reference set. The reference point in the reference set of agricultural cooperatives refers to relatively high operating efficiency of agricultural cooperatives with similar technology. Therefore, the inefficient operating of agricultural cooperatives can learn the business model of reference point in the reference collection to improve its operating efficiency. 
Difference in the multivariate analysis provides the relatively inefficient DMU in the current circumstances, the relevant information may learn about input and output factors and the gap to achieve target, which helps to analyze the extent of spatial improvement. Because of different business model of types of agricultural cooperatives, it is solely on vegetables and fruit and livestock agricultural cooperatives, the results of reference set and variable analysis are illustrated as follows:

\subsubsection{Reference Collection and Variable Analysis of Vegetables and Fruit Agricultural Cooperatives}

If the DMU is relatively efficient, its value is one, representing the DMU falls on the boundary, and becomes the reference object of relatively inefficient DMU.

The table7 lists reference collection of vegetables and fruit agricultural cooperatives to provide some references for people. As Lin River cooperative a example, its reference collection is DMU, the value of DMU is very similar to Lin River cooperative with less investment and get more production. Thus, if the managers want to improve the operational efficiency, they may refer to the operation mode of DMU.

The reference collection of DMU was calculated after the implementation of DEA, which can determine the state and scale of DMU and then be used as the way to improve the operating efficiency. According to calculation, a total ten vegetables and fruit agricultural cooperatives were the constant returns to scale, which has reached its optimum scale of operation. Three vegetables and fruit agricultural cooperatives were decreasing returns to scale status, so if you want to reduce the scale, the marginal returns should be improved to change the operating efficiency. The remaining twenty-nine vegetables and fruit agricultural cooperatives were increasing returns to scale, which can expand their scale of operation in order to improve their marginal returns and efficiency.

Because vegetables and fruit agricultural cooperatives accounted for $69 \%$ are belong to the stage of increasing returns, and the main reason for their inefficient operation is that those cooperatives engaged in production at inappropriate scale, the scale of operation of cooperatives is too small in Langao, which led to its operating efficiency is low, so as to enhance the operational efficiency of agricultural cooperatives, it is very important to expand the size of business. As the previous Pengfang vegetables and fruit agricultural cooperatives a example, this cooperative engaged in production without a optimal scale resulting in the relatively inefficiency of their business, and we can see from table7, the returns to scale is increasing, so we can expand the scale of operation in order to improve operational efficiency.

In terms of variable analysis, we mainly measured vegetables and fruit agricultural cooperatives whose operating efficiency have reached standard, the excessive investment is used as references. Based on the actual situation of Pengfang agricultural cooperative, in order to reach the operational efficiency, in the input factors, operating expenses and management fees should be respectively cut 2,885,130 yuan and 79,721 yuan, they can achieve operational efficiency. In addition, as Langao wind cooperatives a example, compared to other vegetables and fruit cooperatives, its operational efficiency is higher, the relative efficiency of their business who invest in the agricultural cooperatives has reached the optimal state.

\subsection{Business Model of Agricultural Cooperatives}

By AHP and the expert appraisal of input factors, the weights of input factors can be calculated, the agricultural cooperatives, who have reached operational efficiency, will be further measured to select the business model, which will benefit to distinguish the truly efficient agricultural cooperatives.

\subsubsection{Business model of Agricultural Cooperatives}

For the combination of subjective and objective method, to improve the ability to identify operational efficiency of agricultural cooperatives, DEA is used to measure the relative efficiency and APH is also used to assess and select the business model. According to the operation result of software, the weights of input factors is given by experts, namely the value of number of appointment is 0.4629 , the value of asserts is 0.1924 , the value of business expense is 0.2239 , the value of management fees is 0.1208 . Because the value of the consistency index $\mathrm{CR}$ is 0.0001 , it fits requirements of consistent standard, so the results of the questionnaire can be good.

Extend the empirical analysis of DEA of the previous section, we can agricultural cooperatives whose operating efficiency is good. According to the actual situation of input factors and the distribution of weight, the best business model will be assessed and selected. Because each input factor has different unit, in order to obtain the consistent measured basis, this study standardized the input factors and then calculated overall points. As shown in table1, there are fourteen efficient agricultural cooperatives in 2000, after the selection of overall points of input factors, the top of five cooperatives are Lin River pig production cooperative, Fuhong vegetables and fruit cooperative, Hengkang marketing cooperative, Grand Bay vegetables and fruit cooperative and Weir door cooperative. Among them, Lin River pig production cooperative obtained the lowest overall points, in other 
words, this agricultural cooperative is the best business model in this paper.

\subsubsection{Business Model of Vegetables and Fruit Agricultural Cooperatives}

Further explore the business model of vegetables and fruit agricultural cooperatives. From table1 we can see that in ten vegetables and fruit agricultural cooperatives with the efficiency value of one, Crane Luyuan cooperatives is relatively efficient due to little input and its total scores of commentaries are the lowest, which are divided into the most efficient operation of agricultural cooperatives and then become the business model of 42 vegetables and fruit agricultural cooperatives, namely the managers, we can refer to this business model to improve the operational efficiency. In addition, the top of five vegetables and fruit agricultural cooperatives are listed as follows: Gaoqiao vegetables and fruit agricultural cooperatives, Fuhong vegetables and fruit agricultural cooperatives, Qipan vegetables and fruit agricultural cooperatives Yanmen vegetables and fruit agricultural cooperatives and so on.

\section{Conclusions and Recommendations}

The main purpose of measuring the operating efficiency of agricultural cooperatives is to diagnose the status of agricultural cooperatives by the results of assessment, which helps to improve its operating efficiency and the transaction quality of agricultural cooperatives.

\subsection{Conclusions}

The operational efficiency of agricultural cooperatives is assessed by data envelopment analysis, the input and output factors of agricultural cooperatives is selected by fuzzy Delphi method to more accurately measure the operational efficiency of agricultural cooperatives. Finally, efficient cooperatives are further distinguished by AHP to select the best business model. The results of empirical research in this paper are summarized as follows:

First, in order to accurately measure the operational efficiency of agricultural cooperatives by DEA, this study selected input and output factors by fuzzy Delphi method. Among them, the establishment of threshold value need to comply with median score, which is assessed by experts, so in this paper, we selected four input factors and two input factors, the former includes the number of appointment, asserts, business expense and management, the later refers to the number and revenue.

Second, through the operational efficiency of DEA assessment, in terms of the whole agricultural cooperatives, there are fourteen agricultural cooperatives with the operational efficiency value of one in the $104 \mathrm{DMU}$, which indicates those cooperatives have relatively high efficiency. In terms of operational efficiency of vegetables and fruit agricultural cooperatives, there are ten agricultural cooperatives with the operational efficiency value of one in the $42 \mathrm{DMU}$. In terms of livestock agricultural cooperatives, there are twelve agricultural cooperatives with the operational efficiency value of one in the $35 \mathrm{DMU}$, which shows their operation is relatively high efficiency.

Third, from the results of operational efficiency, we can see that regardless of the whole agricultural cooperatives, vegetables and fruit agricultural cooperatives or livestock agricultural cooperatives, if those empirical objects engaged in production at inappropriate scale, they can not get efficient operation. However, reference set and variable analysis may improve their operating efficiency.

Fourth, the weights of input factors are calculated by AHP, which helps to assess and select the best business model in the efficient agricultural cooperatives. On all of the whole agricultural cooperatives, Linhe production cooperatives are the most operational efficiency. Solely on vegetables and fruit agricultural cooperatives, Crane Luyuan cooperatives are the most operational efficiency. On livestock agricultural cooperatives, Lin River pig production cooperatives are the business model.

\subsection{Recommendations}

According to the purpose and conclusions of this study, several recommendations are proposed as follows:

First, at present, the establishment of operating efficiency indicators of agricultural cooperatives still needs to further study and develop, so far there is no one recognized and objective assessment criteria for the measurement of operating efficiency. In this paper, the use of fuzzy Delphi method and the integration of expert opinion selected appropriate input and output factors, in order to accurately measure the operating efficiency of agricultural cooperatives, so it can be used as references for agricultural authorities.

Second, the application of DEA model assesses the operating efficiency of agricultural cooperatives can keep abreast of its case, diagnosis the reasons of inefficient operating and quickly correct the management direction of agricultural cooperatives. Therefore, for relatively inefficient operation of agricultural cooperatives, the number of appointment should be noted, whether asserts, business expense and management fees is appropriate or not to reduce the excessive waste of resources. 
Third, with the changes and impact of external environment, agricultural cooperatives must have the appropriate measurement to provide the best transaction quality. The analysis results of DEA shows that the majority of agricultural cooperatives still have not reached scale efficiency, so we must rethink and adjust the size and scale to enhance their own competitiveness.

Fourth, agricultural cooperatives may measure the results by using DEA evaluation model; agricultural cooperatives can be self-evaluation and correct management direction at any time to know about the cases between cooperatives. Furthermore, combined with AHP, the best operating efficiency of agricultural cooperatives can be selected as a model for their learning and reference.

\section{References}

Cai, R., \& Han, H. (2011). The empirical analysis of influence costs determinants in cooperative: evidence from apple specialized cooperatives in Shandong province. Economic Review, 5, 106-112.

Charnes, A., Cooper, B., Golany, L., \& Stutz, J. (1985). Foundations of Data Envelopment Analysis for Pareto-Koopmans Efficient Empirical Production Functions. Journal of Econometrics, 30(1/2), pp.90-107.

Dong, X. (2010). Empirical research on the relationship between government support and farmer specialty cooperatives' operating performance: based on the mediation of TMT's collective innovation. Statistics of Education, 6, 33-37.

Golany, B., \& Roll, Y. (1989). An Application Procedure for DEA. OMEGA, 17(3), 237-250.

Li, F., \& Zhang, D. (2011).The theoretical explanation of diversified development pattern of Chinese farmer professional cooperatives. The Open Era, 19, 51-53.

Li, Z., Liu, Q., Mao, T., \& Che, S. (2010). Participation in agricultural cooperatives on the household income: as the Danyang City Dantu District a example. Rural Economy and Technology, 21(07), 52-53.

Lou, D. (2010). Empirical research on the relationship between government support and farmer specialty cooperatives' operating performance: based on the mediation of TMT's collective innovation. Statistics of Education, 12, 42-52.

Xu, F., Qiu, L., \& Xiao, L. (2011). Game analysis of the planting and breeding industry farmers' professional cooperative subject relationship under the background of accelerating development in agriculture industrialization. Journal of Jiangxi Agricultural University, 6, 31-35.

$\mathrm{Xu}, \mathrm{H}$. (2010). Analysis of the influencing factors of the farmer cooperatives rural human capital team's formation—-based on Hubei 173 family's date of 5 city. Chinese Agricultural Science Bulletin, 26(35), 342-346.

Zeng, M., \& Yang, Z. (2011) .Research on the benefit distribution model of farmers' specialized cooperatives. East China Economic Management, 25(3), 68-70.

Zhang, X. (2011). The analysis of the factors impacting farmers dependence for professional cooperatives_ based on the survey of 408 villages in 4 provinces including Shandong. Central University of Finance Journal, 1, 44-49.

Zhang, Y. (2011). The empirical analysis on the new agricultural cooperatives based on GIS. Agricultural Research, 3, 7-11.

Zhanga, J., \& Feng, K. (2010).A study on the influencing factors in agricultural integration conducted by farmer's cooperatives.Technical Economics and Management Studies, 3, 148-151. 